\title{
Thermophysical Properties of Lithium Aluminum Germanium Phosphate with Different Compositions
}

\author{
Magnus Rohde ${ }^{1} \cdot$ Yuantao Cui $^{1} \cdot$ Carlos Ziebert $^{1} \cdot$ Hans Jürgen Seifert $^{1}$
}

Received: 8 October 2019 / Accepted: 13 January 2020 / Published online: 30 January 2020

(C) The Author(s) 2020

\begin{abstract}
The NASICON system LAGP $\left(\mathrm{Li}_{1+x} \mathrm{Al}_{x} \mathrm{Ge}_{2-x}\left(\mathrm{PO}_{4}\right)_{3}\right.$ was studied, which is a candidate material for solid state electrolytes. LAGP substrates with different compositions $(x=0.3-0.7)$ were prepared using a melt quenching route with subsequent heat treatment. In order to develop a better understanding of the relationships between the structure and the ionic as well as the thermal conductivity, respectively, the samples were characterized by X-ray diffraction. The ionic conductivity was measured using impedance spectroscopy while the thermal diffusivity and the specific heat were determined by Laser Flash technique and differential scanning calorimetry, respectively. Additionally, thermal analysis was performed in order to evaluate the thermal stability a higher temperatures and, also to identify the optimum temperature range of the thermal post-processing. The measured values of the ionic conductivities were in the range of $10^{-4} \Omega^{-1} \cdot \mathrm{cm}^{-1}$ to $10^{-3} \Omega^{-1} \cdot \mathrm{cm}^{-1}$ at room temperature, but exhibited an increasing behavior as a function of temperature reaching a level of the order $10^{-2} \Omega^{-1} \cdot \mathrm{cm}^{-1}$ above $200{ }^{\circ} \mathrm{C}$. The thermal conductivity varies only slowly as a function of temperature but its level depends on the composition. The apparent specific heat depends also on the composition and exhibits enthalpy changes due to phase transitions at higher temperatures for LAGP samples with $x>0.5$. The compositional dependencies of the ionic and thermal transport properties are not simply correlated. However, the compound with the highest Li-doping level shows the highest ionic conductivity but the lowest thermal conductivity, while the lowest doping level is associated with highest thermal conductivity but the lowest ionic conductivity.
\end{abstract}

Keywords Ionic conductivity $\cdot$ Solid electrolyte $\cdot$ Superionics $\cdot$ Thermal conductivity

Magnus Rohde

magnus.rohde@kit.edu

1 Institute for Applied Materials - Applied Materials Physics (IAM-AWP), Karlsruhe Institute of Technology (KIT), 76344 Eggenstein-Leopoldshafen, Germany 


\section{Introduction}

Within the current state of development, liquid electrolytes are utilized in Li-ion batteries for energy storage with high capacity and power density. These organic liquids serving as the solvents for Li salts are not thermally stable and tend to degrade at higher temperatures. Most of these liquids are flammable which can be an important security issue in high power battery systems. With regard to security and stability, ceramic solid electrolytes offer a number of advantageous properties. Even at higher temperatures they are very stable and do not degrade, and therefore reduce the efforts of a sophisticated thermal management in All-SolidState battery systems.

The lithium aluminum germanium phosphate (LAGP, $\left.\mathrm{Li}_{1+x} \mathrm{Al}_{x} \mathrm{Ge}_{2-x}\left(\mathrm{PO}_{4}\right)_{3}\right)$ $(x=0.3-0.7))$ superionic conductor is one of the candidates for a solid electrolyte in Li-ion batteries. The ceramic ionic conductor is stable in air, in water and at high potentials, respectively. The ionic conductivity exhibits a broad maximum of $\sigma_{\text {Ion }} \approx 10^{-4} \Omega^{-1} \cdot \mathrm{cm}^{-1}$ to $10^{-3} \Omega^{-1} \cdot \mathrm{cm}^{-1}$ [1-3] in the compositional range of $x=0.3-0.7$. LAGP shows a NaSICON structure (Sodium $\left(\mathrm{Na}^{+}\right)$Super Ionic Conductor) with space group $\mathrm{R} \overline{3} \mathrm{c}$ (\#167). It consists of corner sharing $\mathrm{MO}_{6}$-octahedra (with $\mathrm{M}=\mathrm{Ge}, \mathrm{Al}$ ) and $\mathrm{PO}_{4}$-tetrahedra [4-6]. In the un-doped $\mathrm{LiGe}_{2}\left(\mathrm{PO}_{4}\right)_{3}$ (LGP) crystals the Li-ions completely occupy a lattice site between two $\mathrm{GeO}_{6}$-octahedra (Wyckoff position 6b). By aliovalent substitution of $\mathrm{Ge}$ with $\mathrm{Al}$, the $\mathrm{Al}^{3+}$ ions partially occupy the $\mathrm{Ge}^{4+}$ site (Wyckoff position $12 \mathrm{c}$ ). In order to compensate the additional charges, the excess $\mathrm{Li}^{+}$is located at sites with higher energy (Wyckoff position 18e). Lithium ion conduction occurs via hopping between the two sites for which the partial occupation is crucial since it also lowers the activation energy for the $\mathrm{Li}^{+}$migration. Simulation studies show that in $\mathrm{LiTi}_{2}\left(\mathrm{PO}_{4}\right)_{3}$, which also exhibits the NASICON structure, there are diffusion paths along the c-axis due to its lower activation energy for ion migration [7-9].

Although there are numerous studies on the ionic transport in Li-conducting solid electrolytes, the thermophysical properties have been studied only in a small number of publications. Particularly, the thermal transport behavior and the specific heat of LAGP have not been investigated up to now. However, these properties might give additional insights in the physics of superionic conductors.

In the present study, the heat capacity, thermal conductivity and ionic conductivity of LAGP with different compositions were studied. In order to relate these properties to the details of the structure, hot stage XRD was carried out up to $900{ }^{\circ} \mathrm{C}$, which allows us to follow the structural changes due to the heat treatment procedure.

\section{Experimental}

LAGP glasses were prepared using the melt-quench-route, which has been successfully proved in former studies $[6,10] . \mathrm{Li}_{2} \mathrm{CO}_{3}$ (Fluka, 99.0\%), $\mathrm{Al}_{2} \mathrm{O}_{3}$ (SigmaAldrich, $98.5 \%$ ), $\mathrm{P}_{2} \mathrm{O}_{5}$ (Analar Normapur, $99.1 \%$ ) and $\mathrm{GeO}_{2}$ (Alfa Aesar, 
$99.98 \%)$ were used as the starting materials for the glass fabrication. A stoichiometric mixture of these powders was heated up to $1450{ }^{\circ} \mathrm{C}$ with a heating rate of $5{ }^{\circ} \mathrm{C} \cdot \mathrm{min}^{-1}$ in an $\mathrm{Al}_{2} \mathrm{O}_{3}$ crucible and held at that temperature for $10-15 \mathrm{~min}$. The melt was quenched and pressed between two steel plates at room temperature to form a glass disc.

The chemical composition of the prepared glass was analyzed by inductively coupled plasma optical emission spectrometry (ICP-OES, Optima 4300 DV, Perkin-Elmer). The oxygen content was measured using Carrier Gas Hot Extraction (CGHE, TC 600, Leco Co.).

The glass transition $T_{g}$ and the crystallization temperature $T_{c}$, respectively, were determined with a differential scanning calorimeter (DSC 404, Netzsch).

Hot stage XRD was carried out to reveal possible structural changes of the LAGP at elevated temperatures. X-ray powder diffractograms were taken in the temperature range from $630{ }^{\circ} \mathrm{C}$ to $900{ }^{\circ} \mathrm{C}$.

The specific heat was measured using the standard three-step procedure [11] in the DSC (DSC 404, Netzsch for the temperature range $150{ }^{\circ} \mathrm{C}$ to $900{ }^{\circ} \mathrm{C}$ and DSC 204 Netzsch for the temperature range $-25^{\circ} \mathrm{C}$ to $150{ }^{\circ} \mathrm{C}$ ).

The ionic conductivity of glass-ceramics samples was determined by recording impedance spectra in the frequency range $100 \mathrm{~Hz}$ up to $5 \mathrm{MHz}$ using a LCR meter (Sourcetronic 2826) and by evaluating the complex impedance with a matched Equivalent Circuit Modell (ECM) in order to extract resistivity values. The principles of these measurements were explained elsewhere $[12,13]$.

The thermal diffusivity was measured as a function of temperature up to $800{ }^{\circ} \mathrm{C}$ using a Laser Flash device (LFA 427, Netzsch). The thermal conductivity was calculated using the data of the specific heat and density, respectively.

\section{Results and Discussion}

The chemical composition of the different glass batches is shown in Table 1. The differences of the LAGP batches are mainly determined by the varying lithium concentration within the range between $x=0.3-0.7$, namely a glass with low Li content $\mathrm{Li}_{1.31} \mathrm{Al}_{0.42} \mathrm{Ge}_{1.52} \mathrm{P}_{3} \mathrm{O}_{12.1}$, with medium Li content $\mathrm{Li}_{1.55} \mathrm{Al}_{0.52} \mathrm{Ge}_{1.36} \mathrm{P}_{3} \mathrm{O}_{12.0}$, and with high $\mathrm{Li}$ content $\mathrm{Li}_{1.71} \mathrm{Al}_{0.53} \mathrm{Ge}_{1.36} \mathrm{P}_{3} \mathrm{O}_{11.9}$.

The thermal behavior of the as-quenched glass samples during heat treatment measured by the DSC is shown in Fig. 1. The DSC traces reflect the glass transition as well as the crystallization temperatures, respectively. Obviously, the glass transition and the crystallization temperature, respectively, decrease with

Table 1 Compositions of the LAGP batches

\begin{tabular}{lllllll}
\hline Mass \% & $\mathrm{Li}(\%)$ & $\mathrm{Al}(\%)$ & $\mathrm{P}(\%)$ & $\mathrm{Ge}(\%)$ & $\mathrm{O}(\%)$ & Chemical formula \\
\hline LAGPv48 & 2.18 & 2.70 & 22.90 & 26.50 & 43.70 & $\mathrm{Li}_{1.31} \mathrm{Al}_{0.42} \mathrm{Ge}_{1.52} \mathrm{P}_{3.09} \mathrm{O}_{12.1}$ \\
LAGPv51 & 2.57 & 3.39 & 22.60 & 24.10 & 46.20 & $\mathrm{Li}_{1.55} \mathrm{Al}_{0.52} \mathrm{Ge}_{1.39} \mathrm{P}_{3.05} \mathrm{O}_{12.0}$ \\
LAGPv52 & 2.85 & 3.45 & 22.20 & 23.70 & 44.40 & $\mathrm{Li}_{1.71} \mathrm{Al}_{0.53} \mathrm{Ge}_{1.36} \mathrm{P}_{2.99} \mathrm{O}_{11.9}$ \\
\hline
\end{tabular}




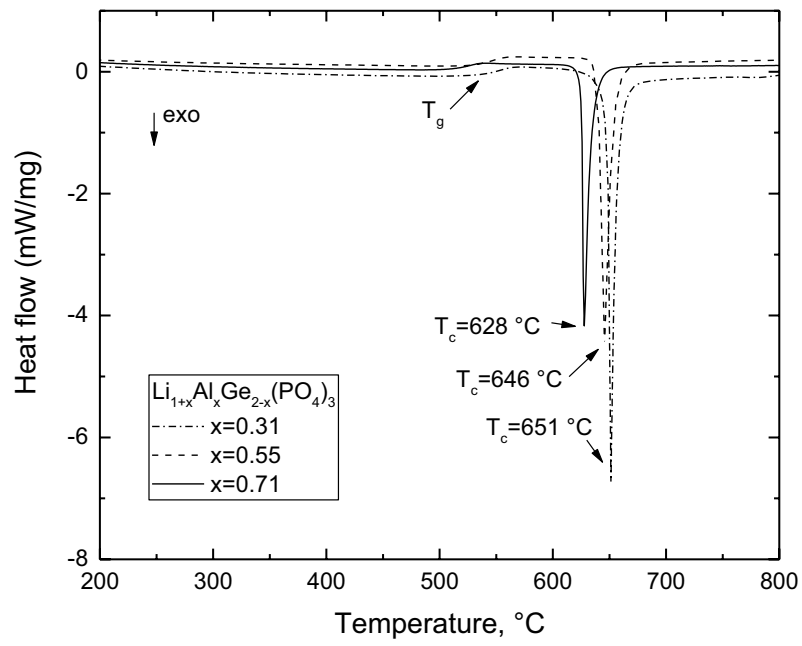

Fig. 1 DSC curve of the as-cast LAGP-glass samples heated up to $900{ }^{\circ} \mathrm{C}$ showing the glass and the crystallization temperature

increasing Li content. However, the difference between both temperatures remain at a nearly constant value of $\Delta T \approx 100 \mathrm{~K}$, which indicates that the thermal stability within this concentration range is not affected [14]. A similar behavior has been found in Li-conducting Li-Borate glasses [15] and in quenched glasses of the system $\mathrm{Li}_{2} \mathrm{O}: \mathrm{Al}_{2} \mathrm{O}_{3}: \mathrm{TiO}_{2}: \mathrm{P}_{2} \mathrm{O}_{5}$ [16] with varying concentrations of $\mathrm{Li}_{2} \mathrm{O}$. In both glassy material systems, the increasing amount of $\mathrm{Li}$ forces the devitrification of the glass.

In order to identify the crystal phases and possible phase transformations during heating HT-XRD was recorded starting from the as-quenched LAGP glass up to a temperature of $900{ }^{\circ} \mathrm{C}$. The results are shown in Fig. 2a-c for the three different compositions. The first XRD-pattern at the bottom of the figures recorded at room temperature exhibit no reflections, which confirms the amorphous or glassy state due to the melt quenching procedure. Diffraction reflections appear at a temperature of $T=630{ }^{\circ} \mathrm{C}$ after an isothermal annealing for $6 \mathrm{~h}$, which is slightly above the onset of crystallization. The hot stage XRD patterns of the glass-ceramic with the lowest $\mathrm{Li}$ fraction reflects the NASICON structure of the parent material $\mathrm{LiGe}_{2}\left(\mathrm{PO}_{4}\right)_{3}$. Furthermore, no foreign phases and structural changes could be observed within the temperature range from $630{ }^{\circ} \mathrm{C}$ to $900{ }^{\circ} \mathrm{C}$, and also not in the diffraction pattern recorded after cooling down to room temperature (top of Fig. 2). Both of the glass-ceramics with the higher Li fraction also show the NASICON structure as the main phase but there are reflections from minor foreign phases visible. The minor phases could be identified as Aluminum phosphate $\left(\mathrm{AlPO}_{4}\right)$ and Lithium pyrophosphate $\left(\mathrm{Li}_{4} \mathrm{P}_{2} \mathrm{O}_{7}\right)$. However, it is interesting to note that the $\mathrm{AlPO}_{4}$ phase appears after cooling down from $900{ }^{\circ} \mathrm{C}$ to room temperature, while the $\mathrm{Li}_{4} \mathrm{P}_{2} \mathrm{O}_{7}$ is only present in a small temperature range between $700{ }^{\circ} \mathrm{C}$ and $800{ }^{\circ} \mathrm{C}$.

The lattice parameters were calculated from the HT-XRD patterns for every isothermal annealing step. The a or b parameter is shown in Fig. 3 as a function of the 
Fig. 2 High temperature $\mathrm{X}$-ray diffraction patterns of $\mathrm{Li}_{1+x} \mathrm{Al}_{x} \mathrm{Ge}_{2-x}\left(\mathrm{PO}_{4}\right)_{3}$ recorded from RT to $900{ }^{\circ} \mathrm{C}$ for three different Li-doping levels: (a) $x=0.71$; (b) $x=0.55$; (c) $x=0.31$
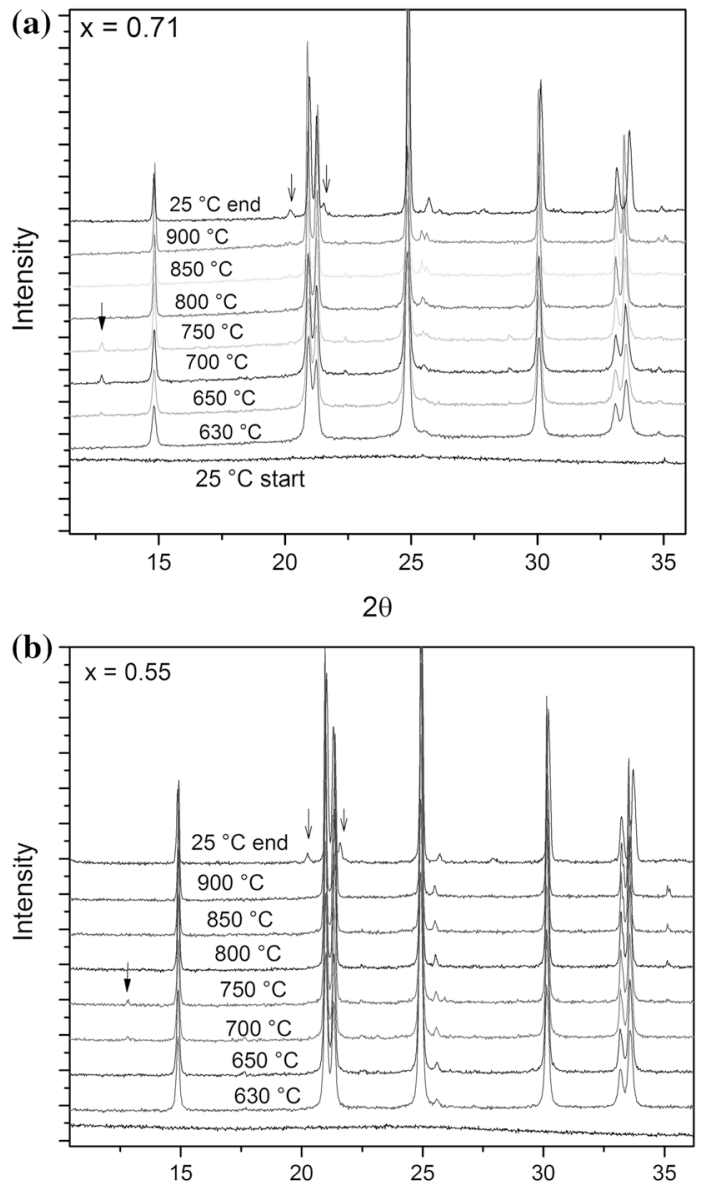

$2 \theta$

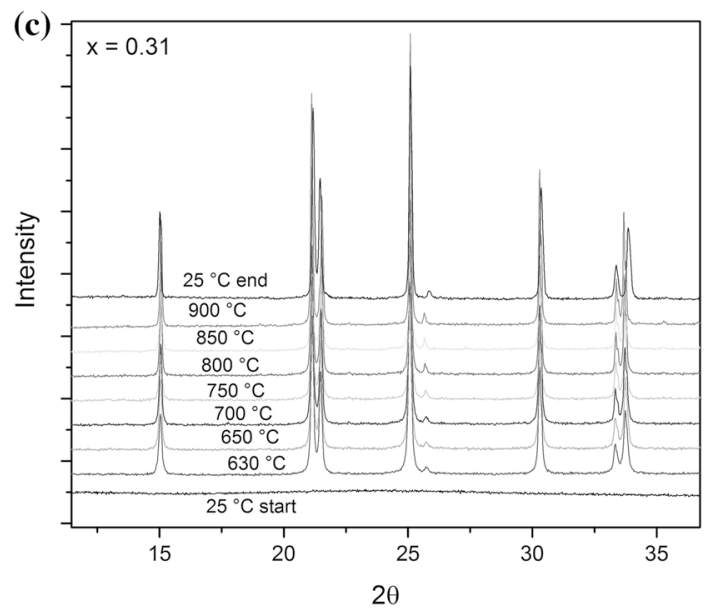




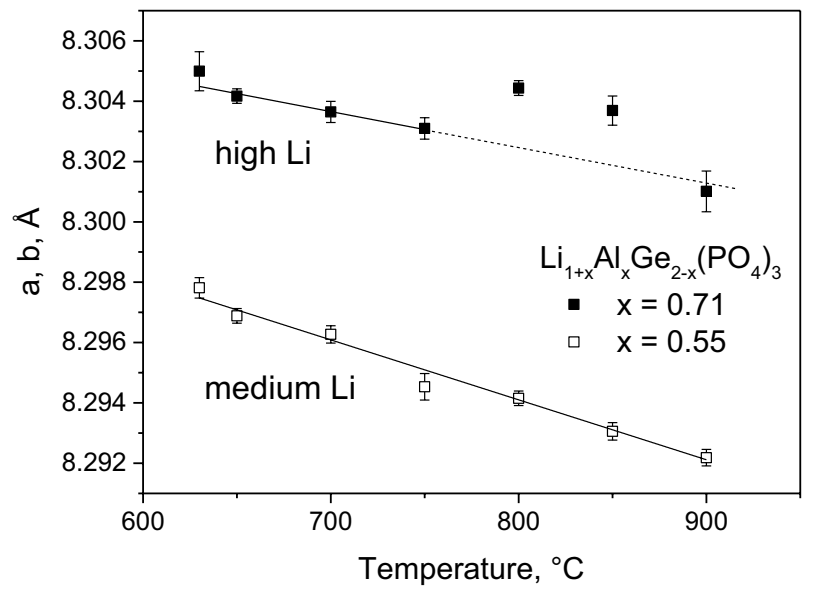

Fig. 3 Lattice parameters a and b of the LAGP calculated from the hot stage XRD results

temperature between $630{ }^{\circ} \mathrm{C}$ and $900{ }^{\circ} \mathrm{C}$. Obviously, the unit cell is shrinking at the base with increasing temperature while it is expanding along the c-axis resulting in an overall expansion of the volume. The lattice parameter a of the LAGP with the lowest and the midrange Li-concentration, respectively, decreases linearly with increasing temperature, which is also true for the sample with high Li-concentration but only up to $750{ }^{\circ} \mathrm{C}$. Above this temperature the values deviates from this linear relationship tending to increasing values. However, the value at $900{ }^{\circ} \mathrm{C}$ "falls back" onto a line extrapolated from linear behavior between $630{ }^{\circ} \mathrm{C}$ and $750{ }^{\circ} \mathrm{C}$.

The results of the heat capacity measurements of the three compositions are shown in Fig. 4 as a function of the temperature. Each measurement was performed on completely crystallized specimen. The sample with the lowest Li-concentration

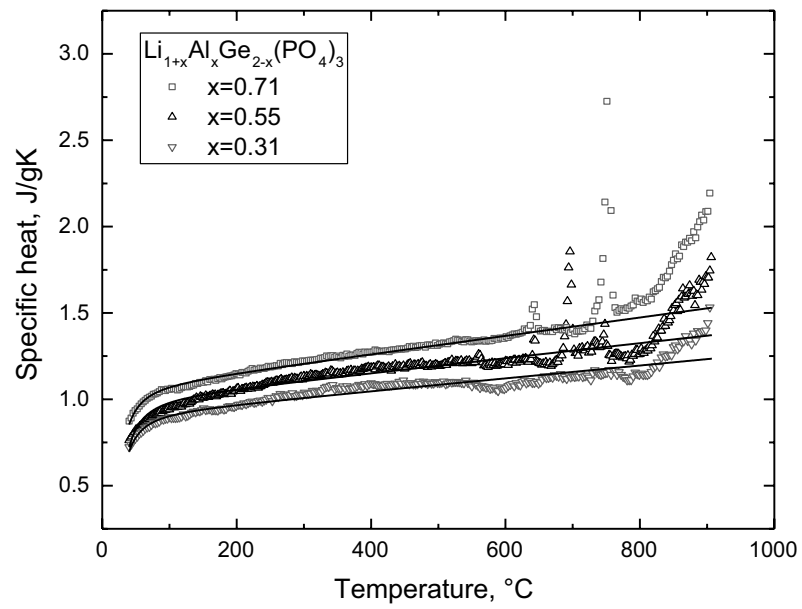

Fig. 4 Heat capacity of LAGP with different $\mathrm{Li}^{+}$doping level 
exhibits an only slightly increasing specific heat within the temperature range from RT to $900{ }^{\circ} \mathrm{C}$. Within this temperature range, there is no evidence of a phase transition, which would be visible as a peak in the heat capacity temperature trace. This behavior is in contrast to that of the compounds with the higher Li-concentration. The $\mathrm{Li}_{1+x} \mathrm{Al}_{x} \mathrm{Ge}_{2-x}\left(\mathrm{PO}_{4}\right)_{3}$ with $x=0.55$ show a series of almost four peaks between $500{ }^{\circ} \mathrm{C}$ and $800{ }^{\circ} \mathrm{C}$, respectively, while the LAGP with $x=0.71$ displays two distinct peaks at approximately $640{ }^{\circ} \mathrm{C}$ as well as $740{ }^{\circ} \mathrm{C}$ which are existing also in the compound with $x=0.55$. It should be noted here that above $740{ }^{\circ} \mathrm{C}$ the thermal induced shrinkage of the a or $\mathrm{b}$ lattice parameter deviates from the linear behavior. Obviously, the enthalpy change visible in the apparent heat capacity data at this temperature is coupled with structural instabilities although this is not associated with a complete transformation of the lattice structure, which is not observed in the XRD data above this temperature. This behavior was also observed in other NASICON systems [16-19] and can be explained by a distortion of the $\mathrm{MO}_{6}$-octahedra, which causes a rotation of the $\mathrm{PO}_{4}$-tetrahedra within the flexible NASICON framework. The degree of distortion and the induced rotation depends obviously on the doping level as well on occupation of the different $\mathrm{Li}$ or Na-sites, respectively.

The straight lines in Fig. 4 are fits to the data in the temperature range from RT to $700{ }^{\circ} \mathrm{C}$ using a Maier-Kelley [20] polynomial:

$$
C p(T)=A+B \cdot T+C \cdot T^{-2}
$$

With $A, B$, and $C$ are constants resulting from the fit procedure to the experimental data. The coefficients $a$ and $b$ are scaling with the Li-doping level, i.e., they growing with increasing doping level which leads to an offset between the $C_{p}$-curves and a stronger slope of the $C_{p}(T)$ curve from $x=1.3$ to $x=1.7$. The constant $C$ does not vary systematically. The values are given in Table 2 . This behavior can be explained by the fact that the increased doping level leads to increasing content of $\mathrm{Li}$ and $\mathrm{Al}$, respectively and a reduction of Ge. Since $\mathrm{Li}$ and $\mathrm{Al}$ - either as elemental metals or as oxide compounds - contribute with relatively high values of the specific heat capacity [21] compared to $\mathrm{Ge}$ or $\mathrm{GeO}_{2}$, a shift to higher $C_{p}$-values of LAGP by Li doping can be expected.

The ionic conductivity of the as-quenched glass appears to be rather low. It scales within a range from $2 \times 10^{-8} \Omega^{-1} \cdot \mathrm{cm}^{-1}$ at $150{ }^{\circ} \mathrm{C}$ to $2 \times 10^{-6} \Omega^{-1} \cdot \mathrm{cm}^{-1}$ at $250{ }^{\circ} \mathrm{C}$. Upon heat treatment at $800{ }^{\circ} \mathrm{C}$ for $6 \mathrm{~h}$, the ionic conductivity increases by several orders of magnitude. The experimental data are shown in Fig. 5 as a log plot of the ionic conductivity as a function of the inverse temperature for the three different Li-concentrations. The lines are the results of a calculation of the ionic conductivity $\sigma$ vs. $1 \cdot T^{-1}$ using the Arrhenius-equation:

Table 2 Values of the coefficients from the MaierKelley polynomial

\begin{tabular}{llll}
\hline Sample & $\mathrm{A}$ & $\mathrm{B}$ & $\mathrm{C}$ \\
\hline $\mathrm{Li}_{1.31} \mathrm{Al}_{0.42} \mathrm{Ge}_{1.52} \mathrm{P}_{3.09} \mathrm{O}_{12.1}$ & 0.90 & $3.710^{-4}$ & $-3.510^{-2}$ \\
$\mathrm{Li}_{1.55} \mathrm{Al}_{0.52} \mathrm{Ge}_{1.39} \mathrm{P}_{3.05} \mathrm{O}_{12}$ & 0.98 & $4.310^{-4}$ & $-4.410^{-2}$ \\
$\mathrm{Li}_{1.71} \mathrm{Al}_{0.53} \mathrm{Ge}_{1.36} \mathrm{P}_{2.99} \mathrm{O}_{11.9}$ & 1.05 & $5.310^{-4}$ & $-3.510^{-2}$ \\
\hline
\end{tabular}




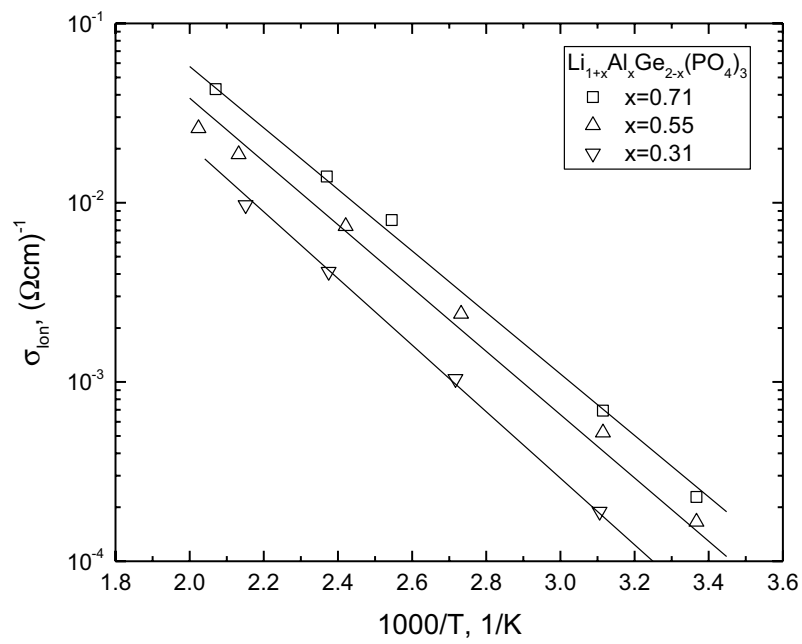

Fig. 5 Arrhenius plot of the ionic conductivity of LAGP

$$
\sigma=\sigma_{0} \cdot e^{-E_{\mathrm{a}} / k_{\mathrm{B}} T}
$$

where $\sigma_{0}$ is the pre-exponential factor and $E_{\mathrm{a}}$ the activation energy, which have been used as variable parameters in Eq. 1 to fit the experimental data. The factor $\sigma_{0}$ can be further formulated [22] in terms of the concentration of free ions $n$ as well as the mean free path $l_{0}$ and the velocity $v_{0}$, which is given by the following equation:

$$
\sigma_{0}=\frac{1}{3}\left[(Z e)^{2} / k_{\mathrm{B}} T\right] n v_{0} l_{0}
$$

The measured ionic conductivity is related to the Li-concentration in the solid electrolyte since the values increase with increasing Li-doping level while the temperature dependence of the three studied systems is nearly the same, i.e., the activation energy $E_{\mathrm{a}}$ varies only between $0.34 \mathrm{eV}$ for the highest doping level of $x=0.7$ and $0.37 \mathrm{eV}$ for $x=0.31$.

The results of the thermal transport measurements are shown in Figs. 6 and 7, respectively. The thermal diffusivity $\alpha$ decreases for all LAGP compositions with rising temperature according to a relation:

$$
\alpha \sim T^{-p}
$$

with the exponent $\mathrm{p}$ varying between 0.08 and 0.11 for the highest and the lowest doping level, respectively. While typical technical ceramics exhibit a temperature exponent $p$ between -1.0 and -0.5 this specific low value in the LAGP-glass ceramic leads to a slowly varying thermal diffusivity as a function of the temperature. Furthermore, it reflects the existence of a high concentration of point defects [23], which is crucial for ionic conducting materials. With the expression for the thermal conductivity $K$ deduced from the Debye kinetic theory of gases [24]: 


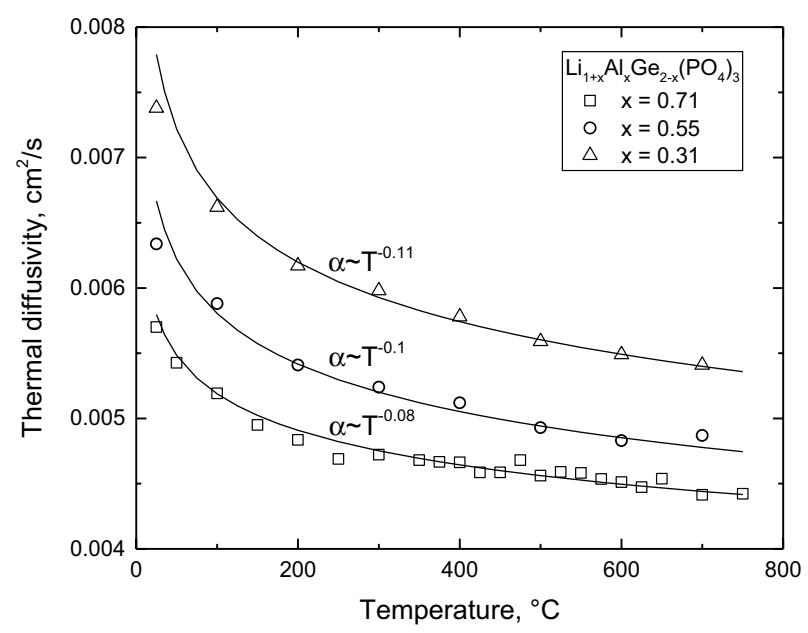

Fig. 6 Thermal diffusivity of LAGP as a function of the temperature for the three different $\mathrm{Li}^{+}$-concentrations

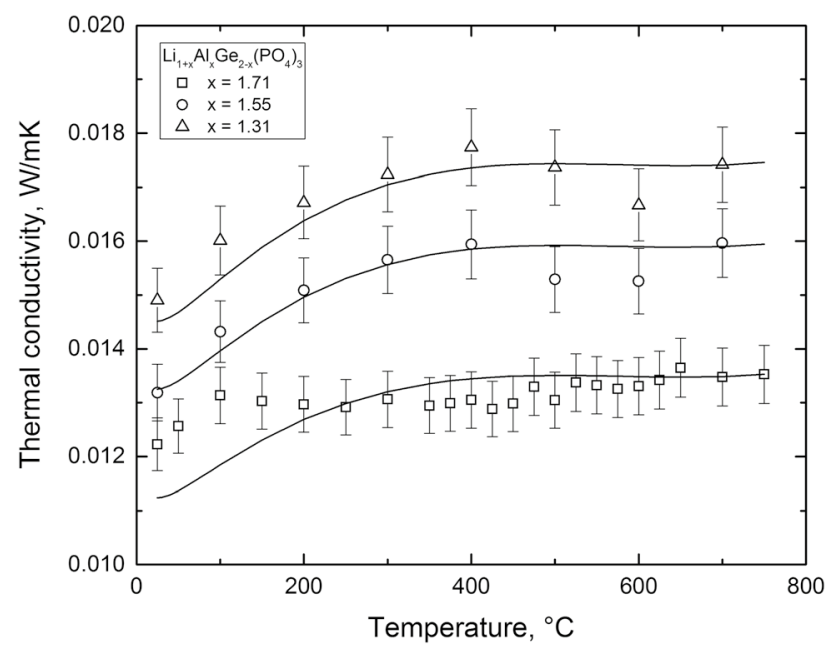

Fig. 7 Thermal conductivity of LAGP as a function of the temperature

$$
K=\frac{1}{3} \cdot C \cdot v \cdot l_{\mathrm{Ph}}
$$

where $C$ is the heat capacity per unit volume, $v$ the average phonon group velocity and $l_{\mathrm{Ph}}$ the mean free path of the phonons between scattering events, it is obvious that the thermal diffusivity $\alpha$ scales also with the phonon mean free path according to: 
Table 3 Density of the samples with different compositions after heat treatment at $800{ }^{\circ} \mathrm{C}$ for $6 \mathrm{~h}$

\begin{tabular}{ll}
\hline Sample & Density $\left(\mathrm{g} \cdot \mathrm{cm}^{-3}\right)$ \\
\hline $\mathrm{Li}_{1.31} \mathrm{Al}_{0.42} \mathrm{Ge}_{1.52} \mathrm{P}_{3.09} \mathrm{O}_{12.1}$ & 3.310 \\
$\mathrm{Li}_{1.55} \mathrm{Al}_{0.52} \mathrm{Ge}_{1.39} \mathrm{P}_{3.05} \mathrm{O}_{12}$ & 3.226 \\
$\mathrm{Li}_{1.71} \mathrm{Al}_{0.53} \mathrm{Ge}_{1.36} \mathrm{P}_{2.99} \mathrm{O}_{11.9}$ & 3.132 \\
\hline
\end{tabular}

$$
\alpha \propto v \cdot l_{\mathrm{Ph}}
$$

without an explicit dependence on the heat capacity as in expression (4). Since the average phonon group velocity is almost independent of the temperature, it is straightforward to assume that the temperature dependence of the thermal diffusivity is related to a slowly decreasing mean free path with increasing temperature.

The thermal conductivity $K$ was calculated using the experimental data of the thermal diffusivity, the specific heat and the density (Table 3) according to:

$$
K=\alpha \cdot c_{p} \cdot \rho
$$

The results are shown in Fig. 7 for the different LAGP compositions or doping levels, respectively. The experimental data show the highest thermal conductivity values for the lowest doping level and the lowest values for the composition with the highest doping level, respectively. The continuous lines in Fig. 7 are results of model calculations using Eq. 5. For this calculation specific heat data were taken from the Maier-Kelley-fit (Eq. 1). The phonon group velocity was estimated using the elastic property data and the density values for $\mathrm{LiTi}_{2}\left(\mathrm{PO}_{4}\right)_{3}$ measured by Jackman et al. [25] which were used for the estimation since there are no data available for LAGP. The phonon mean free path $l_{\mathrm{ph}}$ was adjusted to match the experimental thermal conductivity data assuming the same temperature variation as the thermal diffusivity. For the three compositions we estimated values of $4.1 \AA$ for $x=0.3,3.1$ $\AA$ for $x=1.52$ and $2.6 \AA$ for $x=0.7$ at room temperature, respectively. These values are smaller than the lattice constant, but comparable with the closest $\mathrm{Li}-\mathrm{Li}$ distance $(\approx 3.3 \AA)$ or the closest Li-O distance $(\approx 2.2 \AA)$, which were the results of DFT model calculations [26] and experimental studies [27] on the structural configuration in LAGP.

The thermal transport behavior of superionic conductors has been studied by a number of numerical models [22, 28, 29, 30] using different approaches. The main results of the modeling can be summarized in the following predictions: The thermal conductivity as a function of the temperature should show the same exponential behavior like the ionic conductivity. Within a compositional range of a system, which can be achieved by doping or within a composite, a maximum value of the thermal conductivity should appear which coincides with the maximum of the ionic conductivity. Both predictions result in a strong correlation between the ionic and the thermal transport and would give rise to a so-called "Ionic Wiedemann-Franz-law" [31] which is well known in metals and metallic alloys [32] where it describes the correlation between electronic and thermal conductivity as well as 
the contribution of the conduction electrons to the thermal transport. However, the experimental database of thermal conductivity or diffusivity data, respectively, for Li-based superionic conductors is relatively small. Our results suggest that there is no contribution of the mobile ions to the heat transport in LAGP, which is in agreement with the experimental data of the superionic conductors Lithium iodate and Lithium tetraborate [33] and the data of the NASICON system $\operatorname{Li}_{1.3} \mathrm{Al}_{0.3} \mathrm{Ti}_{1.7}\left(\mathrm{PO}_{4}\right)_{3}$ [34].

A comparison of the ionic and the thermal conductivity, respectively, is shown in Fig. 8 as a function of the Li-doping level $x$ in $\mathrm{Li}_{1+x} \mathrm{Al}_{x} \mathrm{Ge}_{2-x}\left(\mathrm{PO}_{4}\right)_{3}$. It is obvious from this diagram that both transport properties are not correlated, since the ionic conductivity increases with increasing $x$-values while the thermal conductivity decreases. The ionic conductivity changes by a factor of about 3 when the Li content rises from 1.3 to 1.7. Due to the Arrhenius-like behavior its value jumps up by an order of magnitude if the temperature is increased from room temperature up to $100{ }^{\circ} \mathrm{C}$. The thermal conductivity is reduced by $12 \%$ with increasing doping level and the temperature dependence is not very strong since it increases by only $6 \%$ between RT and $100{ }^{\circ} \mathrm{C}$.

Therefore, one can summarize the results of the ionic and the thermal transport measurement that the LAGP sample with highest doping level exhibit also the highest ionic conductivity but the lowest thermal conductivity while lowest doping level is connected to the lowest ionic conduction but with the highest thermal conduction. Increasing the doping level, which introduces a higher number of $\mathrm{Li}^{+}$ions into the NASICON lattice, leads also to a higher concentration of vacancies, which interact with the phonons by scattering effects and disturb the heat transport through the lattice. For the $\mathrm{Li}^{+}$migration, a higher concentration of vacancies is beneficial since it increases the number of sites where an ion can jump into and it further increases the probability that there is an empty site close to an occupied one. Due to these considerations and due to the absence of an Arrhenius-like behavior of the thermal

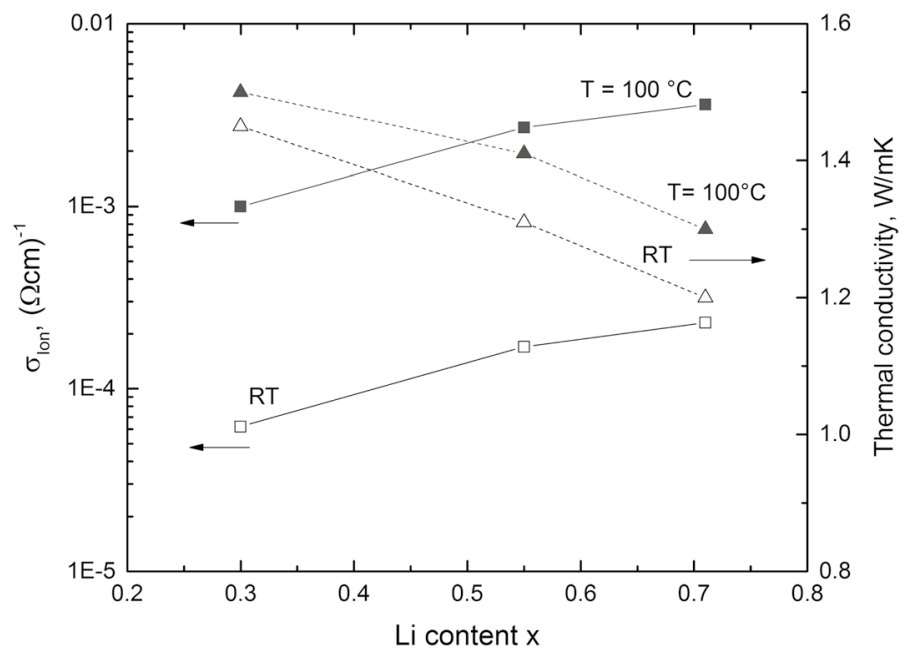

Fig. 8 Comparison of the thermal and ionic conductivity as a function of $x$ in $\mathrm{Li}_{1+x} \mathrm{Al}_{x} \mathrm{Ge}_{2-x}\left(\mathrm{PO}_{4}\right)_{3}$ 
conductivity it can be concluded that the contribution of the ionic transport to the thermal conduction process is negligible in this particular NASICON system.

\section{Conclusion}

In this work, we have studied the ionic and the thermal transport properties of LAGP with different compositions. The specific heat capacity and the thermal conductivity, respectively, were measured for the first time within this NASICON system. The apparent heat capacity scales with the doping level and depends therefore on the Li content. Phase transitions could also be observed in the specific heat data, but only for doping levels which are equal of larger than $x=0.5$. Although the ionic conductivity increases strongly with the Li content and with increasing temperature, the thermal conductivity decreases at higher doping level and varies only slowly with the temperature.

Acknowledgements Open Access funding provided by Projekt DEAL. The authors thank Dr. Bergfeldt (IAM-AWP) for the chemical analysis and Dr. H. Gesswein (IAM-ESS) for the high temperature XRDmeasurements. Financial support by the Helmholtz Association's "Initiative and Networking Fund" in the framework of the Helmholtz Energieallianz "Stationäre elektrochemische Feststoffspeicher und -wandler (HA-E-0002) is gratefully acknowledged.

Open Access This article is licensed under a Creative Commons Attribution 4.0 International License, which permits use, sharing, adaptation, distribution and reproduction in any medium or format, as long as you give appropriate credit to the original author(s) and the source, provide a link to the Creative Commons licence, and indicate if changes were made. The images or other third party material in this article are included in the article's Creative Commons licence, unless indicated otherwise in a credit line to the material. If material is not included in the article's Creative Commons licence and your intended use is not permitted by statutory regulation or exceeds the permitted use, you will need to obtain permission directly from the copyright holder. To view a copy of this licence, visit http://creativecommons.org/licen ses/by/4.0/.

\section{References}

1. M. Schroeder, S. Glatthaar, J.R. Binder, Sol. State Ionics 201, 49 (2011)

2. J.S. Thokchom, N. Gupta, B. Kumar, J. Electrochem. Soc. 155, A915 (2008)

3. J.W. Fergus, J. Pow, Sources 195, 4554 (2010)

4. B. Key, D.J. Schroeder, B.J. Ingram, J.T. Vaughey, Chem. Mater. 24, 287 (2012)

5. M.A. París, J. Sanz, Phys. Rev. B 55, 14270 (1997)

6. C.J. Leo, B.V. Chowdari, G.V. Rao, J.L. Souquet, Mat. Res. Bull. 37, 1419 (2002)

7. G. Nuspl, T. Takeuchi, A. Weiss, H. Kageyama, K. Yoshizawa, T. Yamabe, J. Appl. Phys. 86, 5484 (1999)

8. M. Alami, R. Brochu, J.L. Soubeyroux, P. Gravereau, G. Le Flem, P. Hagenmuller, J. Sol. State Chem. 90, 185 (1991)

9. G. Pang, C. Yuan, P. Nie, B. Ding, J. Zhu, X. Zhang, Nanoscale 6, 6328 (2014)

10. J. Fu, Sol. State Ionics 104, 191 (1997)

11. G. Höhne, W. Hemminger, H.-J. Flamersheim, Differential Scanning Calorimetry (Springer, Berlin, 2010)

12. F. H. Berkemeier, Ionenleitende Borat- und Silikatglasschichten, (PhD thesis, WWU Münster, 2007)

13. C.R. Mariappan, C. Yada, F. Rosciano, B. Roling, J. Pow, Sources 196, 6456 (2011)

14. E. Ferreira, E. Zanotto, S. Feller, G. Lodden, J. Banerjee, T. Edwards, M. Affatigato, J. Am. Ceram. Soc. 94, 3833 (2011) 
15. I. Abrahams, E. Hadzifejozovic, Sol. State Ionics 134, 249 (2000)

16. F. Sudreau, D. Petit, J.P. Boilot, J. Sol. State Chem. 83, 78 (1989)

17. V.I. Pet'kov, E.A. Asabina, V.A. Markin, N.N. Smirnova, J. Therm. Anal. Calorim. 91, 155 (2008)

18. J.P. Boilot, G. Collin, R. Comes, J. Sol. State Chem. 50, 91 (1983)

19. J.P. Boilot, G. Collin, R. Comes, Sol. State Ionics 9-10, 829 (1983)

20. C. Maier, K. Kelley, J. Am. Chem. Soc. 54, 3243 (1932)

21. Y.S. Touloukian, Thermophysical Properties of Matter-TPRC-Data Series Vol. $4+5$ (Plenum Publ. Corp, New York, 1970)

22. M.J. Rice, W.L. Roth, J. Sol. State Chem. 4, 294 (1972)

23. P.G. Klemens, Phys. Rev. 119, 507 (1960)

24. M. Rohde, B. Schulz, in Thermal Conductivity, ed. by J. Cremers, H. Fine (Plenum Press, New York, 1990) pp. 509-520

25. R. Peierls, Ann. Phys. 3, 1055 (1929)

26. S.D. Jackman, R.A. Cutler, J. Pow, Sources 218, 65 (2012)

27. J. Kang, H. Chung, C. Doh, B. Kang, B. Han, J. Pow, Sources 293, 11 (2015)

28. B.E. Francisco, R.S. Stoldt, J.-C. M'Peko, J. Phys. Chem. C 119, 16432 (2015)

29. M. Aniya, T. Usuki, M. Kobayashi, H. Okazaki, Phys. Rev. B 41, 7113 (1990)

30. M. Kobayashi, Y. Yamada, J. Phys. Soc. Jpn. 44, 1734 (1978)

31. J.F. Scott, H.G. Bohn, W. Schenk, Appl. Phys. Lett. 77, 2599 (2000)

32. G.H. Wiedemann, R. Franz, Ann. Phys. Chem. 89, 497 (1853)

33. N.R. Abdulchalikova, A.E. Aliev, Synth. Met. 71, 1929 (1995)

34. E.C. Bucharsky, K.G. Schell, T. Hupfer, M.J. Hoffmann, M. Rohde, H.J. Seifert, Ionics 22, 1043 (2016)

Publisher's Note Springer Nature remains neutral with regard to jurisdictional claims in published maps and institutional affiliations. 